\title{
A Language for the People? Quantitative Indicators of Written dārija and 'āmmiyya in Cairo and Rabat
}

\author{
Kristian Takvam Kindt and Tewodros Aragie Kebede*
}

\section{Introduction}

How frequently are colloquial varieties in Egypt and Morocco ('ämmiyya and dārija) used for writing Arabic? In what contexts? And how many agree that the colloquial has a place as a written language? In this chapter we will address these overarching questions, by drawing on two recently completed, large-scale surveys of the literate population in Greater Rabat and Greater Cairo. Providing representative estimates of writing practices and attitudes in two Arab capitals, this chapter addresses the very real gap in statistical knowledge about how ordinary people relate to writing in the colloquial.

We find that the colloquial varieties are used more than once a week by more than two thirds of literate population in both Cairo and Rabat. There is also a substantial portion of the population in both cities that accept 'ämmiyya/dārija as written varieties. Despite the similarities, we find that both use and acceptance of the colloquial is significantly higher in Cairo compared to Rabat. While one should beware of possible errors in self-reporting, the findings in this chapter prove that colloquial Arabic is widely used and accepted as a written language across different educational levels and socioeconomic backgrounds in both Rabat and Cairo. These findings open up exiting new avenues of research into the dynamics of diglossia in the Arab world.

As noted in the introduction to this volume there exists a growing literature examining the use of colloquial varieties in writing Arabic. The majority of studies on written colloquial Arabic are based on qualitative investigations, so there is a lack of statistical knowledge of the actual frequency of writing colloquial Arabic among ordinary people, as well as of their attitudes towards the colloquial as a written language (for notable contributions, see Parkinson 1991; 1993; 2003; and Belnap \& Bishop 2003).

\footnotetext{
* We would like to thank all the researchers involved in the Language Change project for helping with the design of the surveys on which this article is based.
} 
The existing research on language practices and attitudes therefore gives us limited knowledge of how ordinary people relate to writing in the colloquial, and how widespread and accepted this phenomenon actually is. While quantitative surveys on the topic have been conducted (see Meskine \& Ruiter 2015 and Ibrahim 2013 for two recent examples in Morocco and Egypt, respectively), these studies usually focus on students or other sub-groups of the population and cannot give us any generalizable indicators of language practices or attitudes. There is therefore a need for a statistical investigation into how often colloquial Arabic is written and how people relate to this development. Are we dealing with a marginal phenomenon that no one relates to outside of the cultural elite, or is colloquial Arabic a written language for the people?

\section{Data and Methodology}

The findings are based on results of two surveys carried out in Greater Cairo (2013) and Greater Rabat (2015). Greater Cairo includes parts of Giza and Qalyubiyya in addition to Cairo proper, while Greater Rabat includes the whole of Sale and Temara in addition to Rabat proper (referred to as Cairo and Rabat in the remainder of this chapter). The surveys were based on sample frames from the statistical offices in Egypt and Morocco (Central Agency for Public Mobilization and Statistics (CAPMAs) for Egypt and Office of the High Commissioner for Planning Commission (HPC) for Morocco). This gave us the opportunity to draw a completely random sample of the population, ensuring that the results presented are representative of the population in Greater Cairo and Greater Rabat, respectively.

The persons selected in the survey are between 18 and 64 years of age and have completed preparatory education. The education criterion was added to ensure that we excluded the majority of illiterate people, whose answers were not the main interest of this particular survey. While it may be that many without preparatory education are able to write, it is also a fact that the illiteracy rates in both Egypt and Morocco are much higher among the uneducated portions of the population. The effective sample for Cairo is 2420 and for Rabat 959 persons. The main reason for the lower sample in Rabat was a higher degree of non-response. Further details on how the survey and sampling was conducted can be found in the appendix. The survey covered a host of questions on language use and attitudes. The full list of results is published in Kebede et al. (2013) for Cairo, and Kindt et al. (2016) for Rabat. For a deeper analysis into and explanation of the Egypt survey specifically, see Kindt et al. (2016). 
There are two main advantages of these survey data compared to previous research on the topic. First, the data are representative of their respective populations, giving us generalizable indicators of writing practices and attitudes. To our knowledge, these surveys are the first to be conducted with a representative sample of the general population in any Arab city on the issue of written colloquial Arabic. Second, the surveys allow us to investigate differences in language practices and attitudes between sub-groups of population, for example according to gender, socioeconomic background and age, rather than just focusing on one of these groups.

Despite the clear advantages, quantitative survey results measuring attitudes and practices often face criticism for being inaccurate representations of what people actually think and do. Regarding measurement of attitudes, a common critique is that the survey responses are not complex enough to give a good representation of what people actually think about a subject (Tourangeau \& Yan 2007). In Arabic sociolinguistics this criticism of surveys has been voiced by Walters, who argues that "it is very difficult to determine what speakers specifically have in mind when responding to questionnaire items. If they are asked their opinions about the fuṣhā or French, for example, what kind of fuṣha or French do they 'hear' as they respond? The fuṣhā or French as spoken by whom and under what circumstance?" (Walters 2007:652). In addition, he argues that "speakers will consistently underreport the use of stigmatized varieties (e.g. dialectical Arabic in contrast to the fușhā)" (Walters 2007:652). Walters's criticism notwithstanding, attitude surveys is a common method in all scientific fields, including the natural sciences. The main reason is that attitude questions actually prove to have explanatory power (Bertrand et al. 2001). While they may not give a nuanced account of a person's thoughts about a subject, they do give fairly accurate indications of a person's attitude, if the question is well designed. Instead of discarding attitude questions therefore, we have attempted to meet the criticism of Walters and others by designing not only general, but also specific attitude questions about use of varieties in different contexts.

Regarding self-reported language practices, such questions have been criticized from two angles. First, there is a concern that even if the respondent wanted to, $\mathrm{s} /$ he would not be able to provide a reliable answer to what variety $\mathrm{s} /$ he chooses when and why, because s/he does not remember correctly or is unaware of her or his own practices (Walters 2007: 652). While this argument is relevant, we argue that it is more so for spoken language than written. And it is also more relevant when asking detailed questions about styles of writing. In our survey we do not ask questions about morphological or syntactic details, but very general questions about which language variety (dārija, fuṣhāa) 
or language (Arabic, English, French) respondents use when writing in different contexts. We argue that remembering which language variety ones employs on Facebook is easier than remembering how one usually pronounces a certain word or phrase.

A second and more fundamental line of criticism is that self-reports cannot be trusted because what people say they do is something very different from what they actually do. This argument largely stems from LaPiere's classic study (1934) where he called several hotels in USA and asked if they allowed Chinese guests in their establishment. They all said that of course they did not allow Chinese to stay in their hotel. However, when LaPiere travelled with a Chinese couple to the same hotels, they were allowed to stay in all but one of them. In other words, the hotel managers reported to do one thing, but actually did something very different. This study it has been interpreted as a fundamental epistemological critique, not only of surveys, but of all interviewing techniques trying to understand what people do, based on what they say they do. Some social scientists use findings from LaPiere to argue that we should not take anything people say they do as being related to what they actually do, but rather see it only as a narrative, or ideological construction that is "abstracted from lived experience" (Jerolmack \& Khan 2014). A version of this argument has been raised by Milroy and Milroy (1999:15-16) in sociolinguistics, who argue that "statistical counts of variants actually used are probably the best way of assessing attitudes."

In our view, to dismiss self-reported practices as unrelated or weakly related to actual practice is wrong, both epistemologically and empirically. Even LaPiere (1934) did not argue that all self-reports were useless, but rather argued that self-reports were useful for a number of purposes. For questions on nonsensitive issues, the errors in self-reporting are generally proven to be small or manageable (Viasey 2014). We therefore see no reason not to trust the responses of non-sensitive questions in the survey, such as reading practices, information on education level, age etc. When dealing with sensitive questions, there is reason to be wary of biases. (Tourangeau \& Yan 2007). However, the empirical literature on the subject argues that even sensitive questions on self-reported practices tend to be more reliable than critics think (Schuman \& Johnson 1976, Viasey 2014:1). The critics (see Jerolmack \& Khan 2014 for a recent example) overstate the reluctance people have in reporting what they do. The link between self-reporting and actual practices is actually very high when asking for self-reports on social practices. Election surveys for example, which ask people about what they intend to vote are remarkably accurate, with only a few percentages in reporting errors, despite the obvious sensitivity in saying which party one votes for (Silver 2012). A recent experiment on the link between 
reported action and actual for sensitive questions found that the correlation between self-reported action and actual action was at 0.85 (where 1 is perfect correlation), based on nine sensitive survey questions on grades in University (Kreuter et al. 2008) In other words, the research indicates that the vast majority of survey respondents actually tell the truth, even when questions are sensitive (Viasey 2014). Taking this result into consideration, it becomes difficult to argue that self-reporting is not at all reflective of actual practices. Therefore, rather than discard questions on self-reported action, we will assess which questions might be sensitive, and review in which direction to suspect a bias, after the presentation of the findings.

\section{Findings}

\section{Background Characteristics}

We begin by presenting some basic background characteristics of the sample, seen in table 1.1. As mentioned in the previous section, all the findings are representative of the population of Rabat and Cairo, for those between 18 and 64 years of age, who have completed preparatory education. Or to put it differently, it is representative of the literate population of these two cities. The sample size in Cairo is 2450 while it is 959 in Rabat. The reason for the discrepancy is mainly due to lower response rates in Rabat. In Cairo, the response rate was at 98 percent while it was at 60 percent in Rabat (for more details see appendix).

As is clear from table 1.1, all age groups, different levels of education, and both sexes are well represented. In both cities we are dealing with a young population, with the majority under 34 years old. Almost all of them have gone to public school, and the vast majority had Arabic as their main language of instruction in school. Only 12 percent of the Rabat population were taught in schools where French was the main language of instruction.

In the following, we present findings from the survey on writing practices, attitudes to the colloquial in writing and classifications of fuṣha and the colloquial. Finally we look at whether attitudes and practices vary according to age, socioeconomic position, gender and education.

\section{Writing Practices}

The frequency of writing in different languages/varieties in Cairo and Rabat is presented in figure 1.1. The question posed was "how often do you write in the following languages". "Often" means that respondents reported to write the language in question "every day", or "at least once a week". The question is not about writing in a specific context, but writing in general. 
TABLE 1.1 Background characteristics

\section{Cairo Rabat}

Age

\begin{tabular}{lrr}
$18-34$ & 55 & 66 \\
$35-49$ & 30 & 23 \\
$50-64$ & 15 & 11 \\
Total & 100 & 100 \\
\hline
\end{tabular}

Sex

\begin{tabular}{lrr} 
Male & 40 & 49 \\
Female & 60 & 51 \\
Total & 100 & 100 \\
\hline
\end{tabular}

Education

\begin{tabular}{lrr}
\hline Preparatory & 20 & 44 \\
Secondary & 53 & 37 \\
University & 27 & 19 \\
Total & 100 & 100 \\
\hline
\end{tabular}

Type of school

\begin{tabular}{lrr}
\hline Public & 92 & 96 \\
Private & 6 & 4 \\
Other & 2 & 0 \\
Total & 100 & 100 \\
$\mathrm{~N}=$ & 2408 & 959 \\
\hline
\end{tabular}

Language in school

\begin{tabular}{lrr}
\hline Arabic & 97 & 87 \\
French & 0 & 12 \\
Others & 3 & 2 \\
Total & 100 & 100 \\
$\mathrm{~N}=$ & 2411 & 959 \\
\hline
\end{tabular}




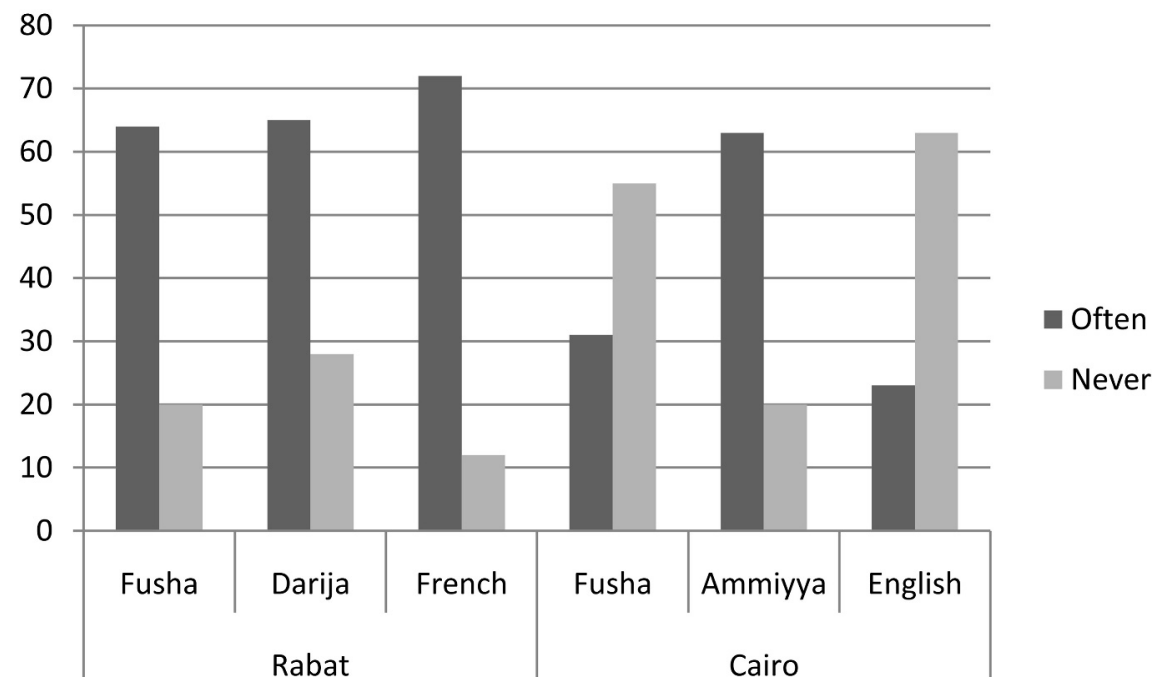

FIGURE 1.1 Writing practices in Rabat and Cairo (in percent)

The table shows that the colloquial variety is used often by a majority of the population in both Cairo and Rabat. In Cairo, 'âmmiyya is by far the most used written language with two thirds writing it often. Fuṣhā is used much less, with around a third claiming to never write in that variety. English is the least used of the three, with around a fifth of the population writing English frequently. In Rabat, French is the most used written language, closely followed by dārija and fuṣha $\bar{a}$. The main difference between Rabat and Cairo is not the frequency of writing the colloquial, but rather that the colloquial is not dominant compared to fuṣhā and French.

The natural follow-up question is what people use these different languages/varieties for. That is presented in table 1.2 for Rabat and table 1.3 for Cairo.

The answer options in the Rabat and the Cairo survey were slightly different, in the sense that the question in Cairo was which Arabic variety they used, while in Rabat it was asked for which language, opening up for French and English. In this sense, the tables are not directly comparable. If we focus on the use of the colloquial however, there are some differences between the two cities. In Rabat it is clear that dārija is mainly used for writing on Facebook and sMs, but not so much for e-mails, work or school-related writing. In Cairo, 'ämmiyya has somewhat wider usage, being used also for e-mail and to a certain extent work and school-related issues. This makes sense, keeping in mind that 'ämmiyya is used more often than fușhā and English in Cairo, whereas dārija is by no means dominant compared to fuṣh $\bar{a}$ and French in Rabat. This picture 
TABLE 1.2 Rabat: What language do you use when using ...?

\begin{tabular}{lcrrrr}
\hline & Facebook & E-mail & Work & School & SMS \\
\hline Fușhā & 19 & 15 & 39 & 52 & 17 \\
Dārija & 60 & 8 & 5 & 4 & 56 \\
French & 19 & 76 & 54 & 42 & 26 \\
English & 1 & 1 & 2 & 2 & 1 \\
\hline Total & 100 & 100 & 100 & 100 & 100 \\
N = & 680 & 630 & 632 & 445 & 895 \\
\hline
\end{tabular}

TABLE 1.3 Cairo: What language do you use when using ...?

Facebook E-mail Work School SMS

\begin{tabular}{lrrrrr}
\hline Only fuṣhā & 5 & 10 & 42 & 40 & 5 \\
Only ámmiyya & 52 & 45 & 31 & 18 & 68 \\
Mix & 43 & 45 & 27 & 42 & 27 \\
\hline Total & 100 & 100 & 100 & 100 & 100 \\
$\mathbf{N}=$ & 757 & 636 & 730 & 293 & 1888 \\
\hline
\end{tabular}

is confirmed if we look at tables 1.4 and 1.5, presenting answers to the question "what was the last thing you wrote in the following language?"

Tables 1.4 and 1.5 are directly comparable, with the exception that SMS was not one of the answer categories in Rabat. In Rabat almost all the respondents reported to either have written on Facebook or a personal letter in dārija, while the respondents in Cairo reported to have used ämmiyya for wider set of purposes, including work and to some extent school assignments.

In short, writing in the colloquial is reported to be widespread in both cities, being the most used written language in Cairo and equally much used as French and fuṣhā in Rabat. While previous research has acknowledged that it is employed, this is the first representative estimate showing that colloquial varieties are actually used often, for writing, by over two thirds of the population. While ámmiyya dominates writing practices in Cairo, and is used for a variety of purposes, the usage of dārija is narrower in Rabat, being employed mainly for Facebook, Twitter and personal notes. 
TABLE 1.4 What was the last thing you wrote in ...?

\begin{tabular}{lrrr}
\hline Cairo & Ámmiyya & Fuṣha & English \\
\hline Work related letter or notice & 12 & 39 & 17 \\
Text messages & 37 & 8 & 12 \\
Facebook and twitter messages & 21 & 8 & 25 \\
School assignments & 5 & 19 & 22 \\
Personal writings/notes & 16 & 13 & 9 \\
Other & 6 & 6 & 0 \\
E-mails & 1 & 1 & 7 \\
Personal letter & 1 & 2 & 1 \\
Creative writings & 0 & 2 & 0 \\
\hline Total & 100 & 100 & 100 \\
\hline
\end{tabular}

TABLE 1.5 What was the last thing you wrote in ...?

\begin{tabular}{lrrr}
\hline Rabat & Därïa & Fuṣha & French \\
\hline Facebook and twitter messages & 51 & 13 & 17 \\
Personal letter & 43 & 9 & 19 \\
Comments on Youtube videos & 0 & 18 & 22 \\
School assignments & 1 & 19 & 20 \\
Personal writing/notes & 2 & 16 & 4 \\
Autre & 2 & 12 & 5 \\
Work related letter, notice, etc & 1 & 8 & 4 \\
E-mail & 0 & 2 & 7 \\
Creative writings & 0 & 3 & 1 \\
\hline Total & 100 & 100 & 100 \\
\hline
\end{tabular}

\section{Language Attitudes}

How is the use of colloquial varieties perceived? In figure 1.2, we see that the vast majority think that 'āmmiyya or dārija is easier to understand than fuṣhā. In this, the respondents in Cairo and Rabat agree.

Regarding whether the language has a place as a written language however, the population in the two cities differs quite markedly. In figure 1.3 we see the 


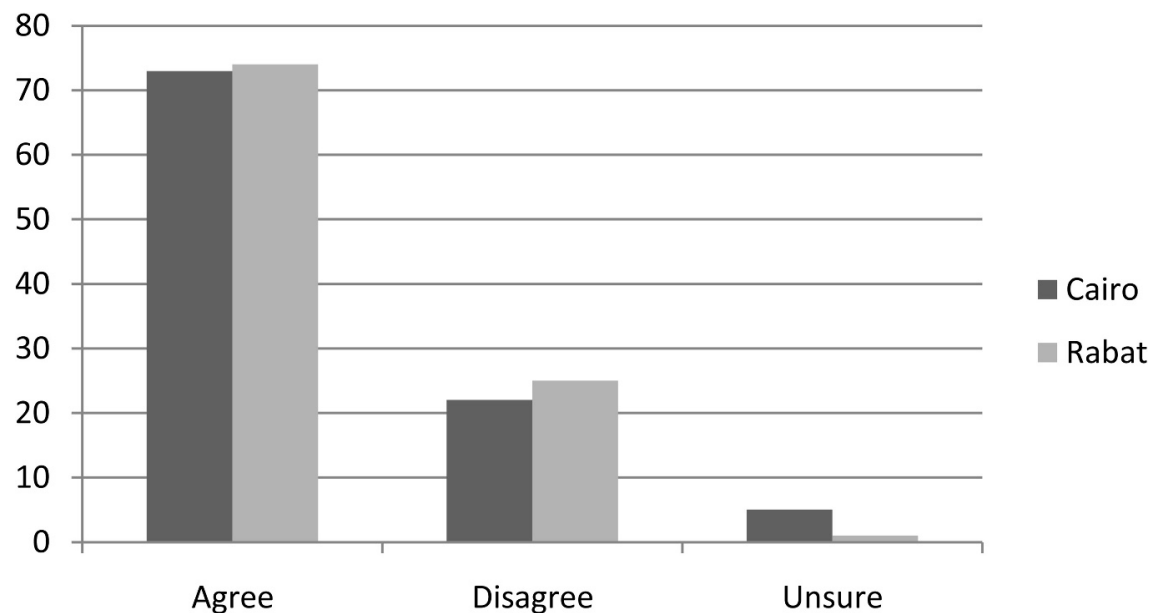

FIGURE 1.2 'Āmmiyya is easier to understand than fuṣhāa

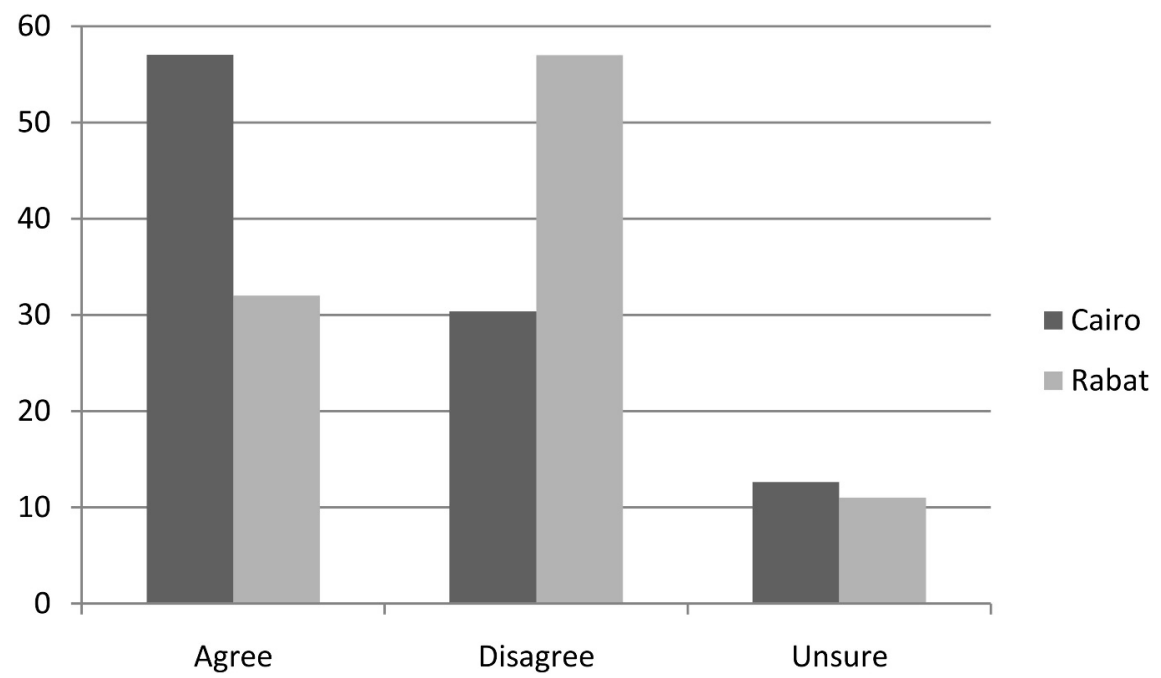

FIGURE 1.3 'Āmmiyya/dārija has a place as a written language

answers to the question of whether 'âmmiyya and dārija respectively has a place as a written language.

The attitude toward the colloquial as a written language follows opposite patterns in Cairo and Rabat. Around 60 percent of the population in Cairo thinks that 'âmmiyya has a place as a written language, while around a third disagrees. The reverse is true for därija in Rabat. In both cities, around 10 percent are unsure or answered "don't know”. The seeming trend that the population in 


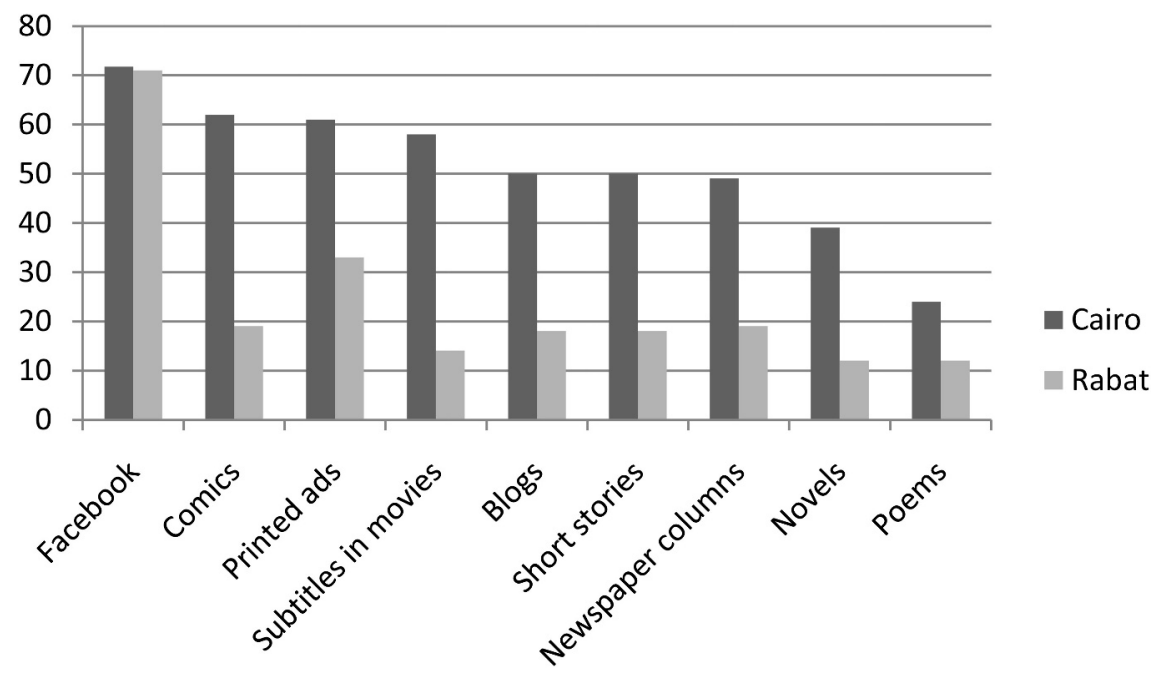

FIGURE 1.4 Percentage who agrees 'āmmiyya/dārija is suitable on the following platforms

Rabat is more conservative in their attitudes towards the colloquial as a written language is confirmed by the findings presented in figure 1.4.

While the respondents in Cairo and Rabat generally think that 'ammiyya is suitable for Facebook, the Rabat population is skeptical towards the use of dārija in any other platforms. In Rabat they are even skeptical of using dārija in media often associated with the colloquial, such as ads. In Cairo on the other hand, over half the population view 'ämmiyya as suitable for comics, printed ads, subtitles, blogs short stories and newspaper columns. It is only poems where less than a third of the Cairenes think that 'ammiyya is not suitable. Despite the differences, it is important to keep in mind that even in Rabat, around one third of the population thinks dārija has a place as a written language, which is a significant portion of the population. But as with writing practices, dārija seems to be present, but more confined compared to Cairo, where 'ammiyya is widely written and accepted.

The relatively high acceptance of $d \bar{a} r i j a$ as a written language does not mean that the acceptance or status of fuṣha is diminishing. For Egypt we see in table 1.6 that the vast majority think fuṣhā is an important language both for oneself and for Egypt.

Table 1.7, similarly show that more people want fuṣha to be the main language of instruction in school, rather than 'ämmiyya.

For Rabat, we included some more direct questions on the status of fuṣha that were not included in the Cairo survey. Table 1.8 shows the reactions to two statements. Statement 1: "Fusha is the only language that should be used 
TABLE 1.6 Importance of fuṣhā to yourself and to Egypt

\begin{tabular}{lrr}
\hline Importance of fuṣha to: & Oneself & Egypt \\
\hline Very important & 40 & 70 \\
Important & 33 & 23 \\
Neither important nor unimportant & 7 & 2 \\
Less important & 17 & 4 \\
Not important & 3 & 1 \\
\hline $\mathrm{N}=$ & $\mathbf{2 4 1 6}$ & $\mathbf{2 4 1 6}$ \\
\hline
\end{tabular}

TABLE 1.7 Which language should be used in the classroom?

Secondary Preparatory Primary

\begin{tabular}{lrrr}
\hline Fușhāa & 35 & 34 & 33 \\
'āmmiyya & 21 & 22 & 28 \\
Both & 40 & 41 & 36 \\
English & 4 & 3 & 3 \\
\hline $\mathrm{N}=$ & 2.348 & 2.400 & 2.389 \\
\hline
\end{tabular}

TABLE 1.8 Attitudes to fuṣhā in Rabat

Statement 1 Statement 2

\begin{tabular}{lrr}
\hline Agree & 77 & 60 \\
Disagree & 17 & 26 \\
Unsure & 7 & 14 \\
\hline Total & 100 & 100 \\
$\mathbf{N}=$ & 956 & 956 \\
\hline
\end{tabular}




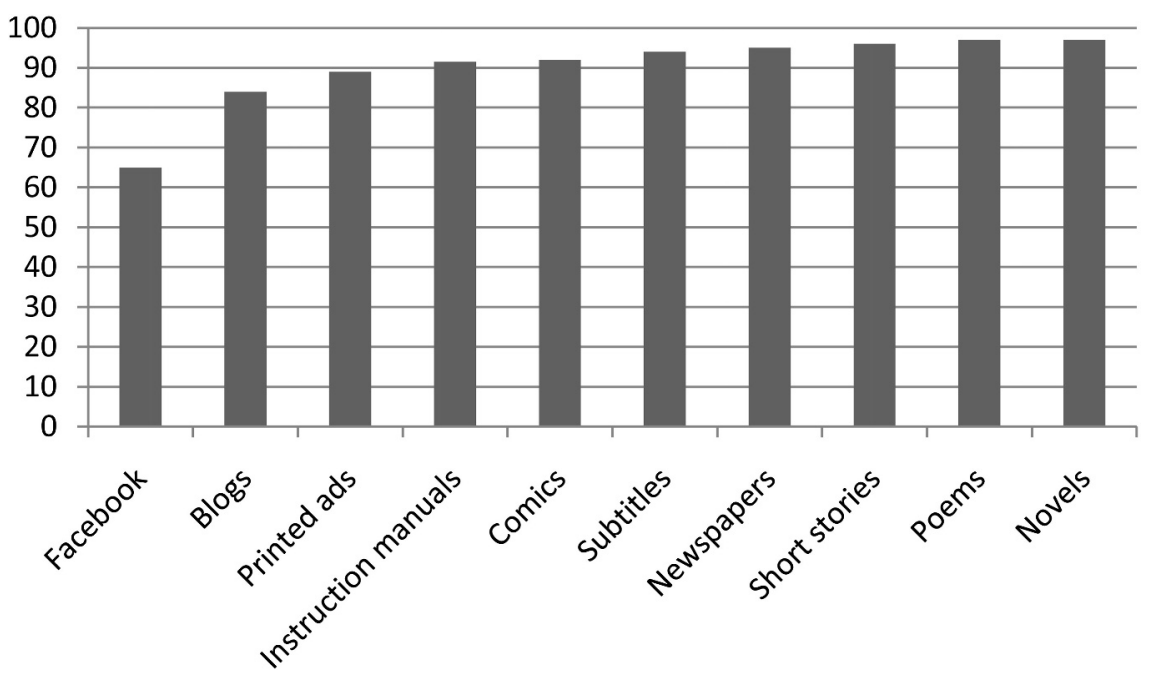

FIGURE 1.5 Percentage who think fușhā is suitable within the following platforms

for writing Arabic". Statement 2: "It is more important to master writing and reading Fusha than writing and reading French".

In Rabat we also asked if fuṣhā was a suitable variety for a number of different platforms. The results are shown in figure 1.5. Both table 1.8 and figure 1.4 confirm that fuṣha is a highly valued variety in Rabat, deemed suitable by almost all on all platforms, and considered more important to learn than French.

\section{Implications of Age, Education and Sex}

Who writes the colloquial and who finds it suitable as a written language? As mentioned in the introduction, an advantage of this survey is that we can look into differences between sub-groups of the population. Do we see clear patterns in terms of which social groups write the colloquial and find it acceptable as a written language?

All the figures presented below are based on regression analysis. The presented results are the estimated likelihood for either writing often in the colloquial or accepting the colloquial as a written language, for different sub-groups of the populations. In all the regressions we controlled for age, socioeconomic status, education and gender (for full tables and methodological explanation, see appendix).

In figure 1.6 we see the estimated likelihood of writing often in the colloquial for people with different education levels, controlling for age, income and gender. The most important finding in this graph is the lack of large differences between those with higher education and those without. In general, people 


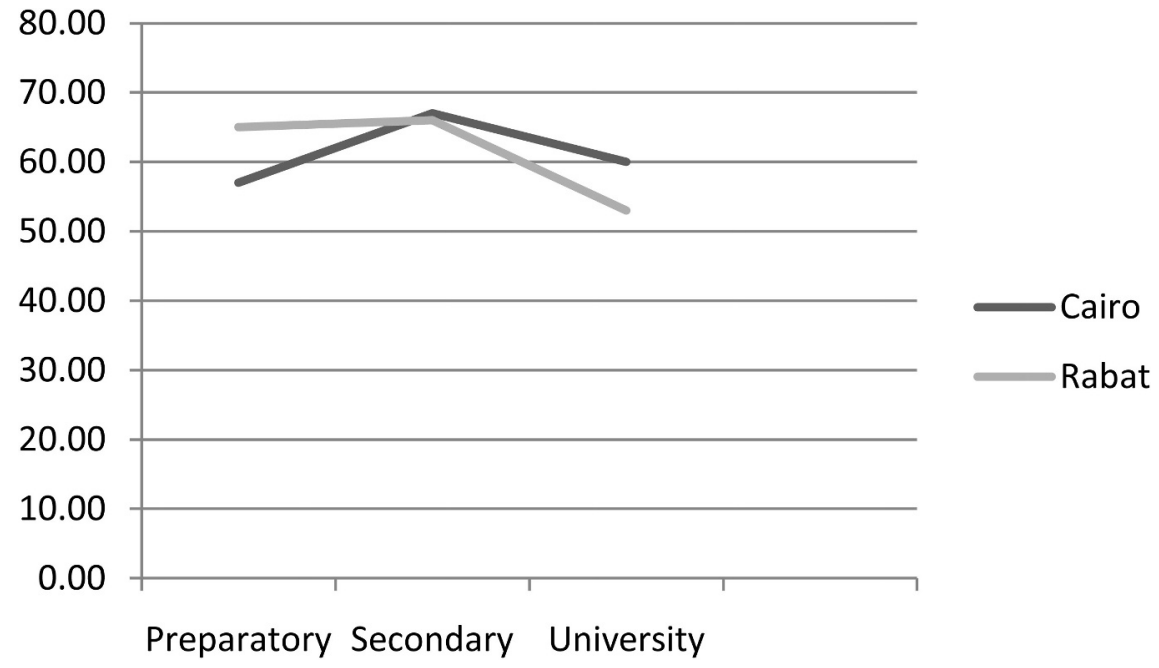

FIGURE 1.6 Likelihood of writing colloquial for different education levels

are likely to write in the colloquial across different levels of education. In Cairo, the small differences observed in the figure are not statistically significant. For Rabat, there is a statistically significant downward trend for those with university education. While those with only preparatory education are 65 percent likely to write often in därija, those with university education are only slightly above $5^{0}$ percent likely to do the same.: The less educated parts of the population write more frequently in the colloquial than those with a university degree.

In figure 1.7 we see the likelihood for writing colloquial across different age groups.

We see a clear trend in both cities that young people write much more frequently in the colloquial compared to older people. As with education, the clearest trend is visible in Rabat, where people are 80 percent likely to write in därija if they are between 18 and 34 years old, while there is only a 23 percent chance of doing the same if they are more than $5^{0}$ years old. In Cairo, there is around 70 percent likelihood of writing 'ämmiyya for 18 to 34-year-olds, while the likelihood of writing 'ämmiyya for those who are over 50 years old is slightly below $5^{\circ}$ percent. All the differences in this regression are statistically significant.

Regarding gender, there is no statistically significant difference for Rabat. In Cairo however, there is a slightly higher likelihood for writing 'ämmiyya often for men than for women. We also analyzed the importance of income and socioeconomic status, but they were not significant factors when controlling for age and education. 


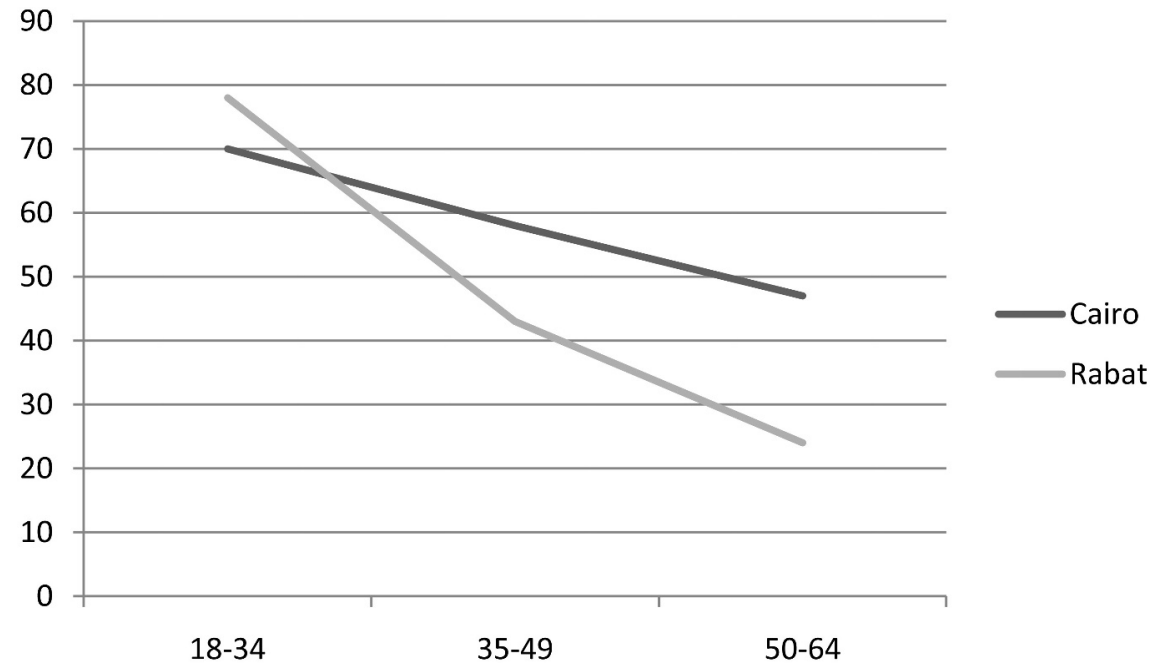

FIGURE 1.7 Likelihood of writing colloquial for different age groups

The picture that emerges is that in both Cairo and Rabat, it is young people who are the most frequent writers of 'ammiyya. The implications of the finding that younger people write more frequently in the colloquial then older people are difficult to assess. Either, the young people write more in the colloquial because they are young, but they will stop doing so and write more fuṣha when they get older (an age effect). But the explanation might also be connected to new technologies and developments in recent decades. This would perhaps mean that the young today will continue to write in the colloquial when they get older, and the new generations may follow them, implying more frequent usage of the colloquial in all age groups in a couple of decades (a cohort effect). Both scenarios are possible, and it is impossible to determine which is true based on the data from this survey. All we can say at this point is that 'ammiyya is quite frequently used in all social groups in Cairo, while the educated and older population of Rabat is much more skeptical than the young. This corroborates the finding that use of the colloquial is present, but more confined in Rabat compared to Cairo.

Turning to attitudes, we see the importance of education for having positive attitudes to the colloquial as a written language in figure 1.8.

The level of acceptance of the colloquial is generally higher in Cairo than Rabat, as we have seen. Interestingly we see that the highly educated are less likely to accept the colloquial as a written language, pointing toward the existence of an elite with a more conservative outlook on language compared to the less educated parts of the population. In Cairo, those with a preparatory edu- 


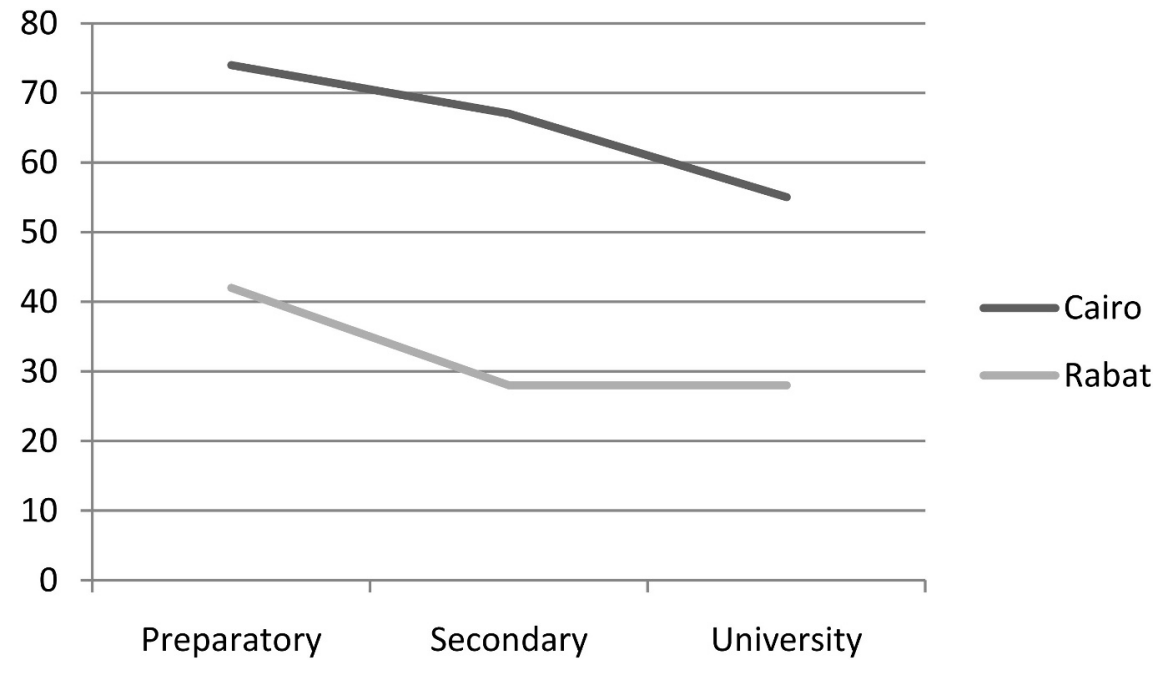

FIGURE 1.8 Likelihood of accepting colloquial as a written language across education levels

cation have a 75 percent chance of accepting 'āmmiyya as a written language while the likelihood of accepting 'ámmiyya is around 20 percent less for those with a university degree. In Rabat, those with preparatory education have over 40 percent chance of accepting dārija as a written language, while less than 30 percent of those with a university education do the same.

Neither gender, income nor age were significantly correlated with attitudes towards 'àmmiyya or dārija as a written language. Generally therefore, the Rabat population is more conservative than the Cairenes, and the attitudes are fairly stable in all social groups, with a minor exception of education, where the educated are more conservative.

\section{Can We Trust the Results?}

What do these results mean? Can we deal with them as accurate representations of language practices and attitudes? As mentioned above, a real concern in all survey research is that there are biases in reporting on sensitive questions. A sensitive survey question is defined in the literature as a question where "there are clear social norms regarding a behavior or attitude" and where "answers reporting behaviors or attitudes that conform to the norms are deemed socially desirable, and those that report deviations from the norms are considered socially undesirable." (Tourangeau \& Yan 2007:860). In our case, asking about how often you write in different varieties might be interpreted as 
sensitive questions. The assumption is that there are clear social norms which say that fuṣha is the only variety suitable for writing. Following this logic, we should expect that people underreport their use of colloquial varieties, as it is socially undesirable according to this norm, and over-report the use of fuṣha $\bar{a}$, as this is seen as socially desirable according to the norm.

Judging from our findings however, there are reasons to doubt how strong the social norm against use of the colloquial really is. When we see that in Cairo over 70 percent of the population accepts 'amminya as a written language and a third of the Rabat population do the same, can we still say that it is a clear social norm against writing colloquial? And even if it is, this would imply that the estimates for writing dārija and 'ämmiyya are conservative, and that people actually write even more than what they admit to in this survey. In terms of their reported fușhā practices, it seems more relevant to discuss bias. Judging from the Rabat results, fewer people accept dārija as a written language. This does not seem to influence their reported practices of writing dārija, but it might have influenced their self-reports of writing in fuṣha $\bar{a}$. The reported practices of fuṣhā are much higher in Rabat than in Cairo. No previous research indicates that this should be the case, which may indicate that is an effect of a social norm saying that it is socially desirable to write fuṣha . In other words, the sensitivity of self-reporting language practices does not necessarily lie in writing colloquial, but rather in not writing fuṣhā. Practices of fușhā may be over-reported in Rabat, rather than dārija being under-reported. In any case, it does not seem likely that biased reporting has altered the general direction of our results.

Another factor that may potentially bias the results is the respondents' definitions of 'āmmiyya, dārija and fușhā. The definition of what constitutes fuṣhā is not at all clear, and by extension, the boundaries of 'ämmiyya or dārija are not clear, either. In a series of linguistic experiments with both written and spoken discourse in Egypt, Dilworth Parkinson showed that a wide array of terms exists among Arab scholars and lay people alike to designate different stylistic levels and registers of written Arabic (Parkinson 1991, 1993, 2003). Parkinson comments that "people do not agree on a term, and (...) they do not agree on what specific part of the communicative continuum, i.e., what specific varieties, any particular term should refer to" (Parkinson 1991:33). In addition, different people may mean different things by referring to 'fușha $\bar{a}$ : For some, only the most eloquent prose qualifies as fușha, while perhaps others view fuṣha as almost everything that is written down with Arabic letters (Parkinson 1991:34). In other words, it is not necessarily clear what literate Egyptians and Moroccans mean when they talk about writing and talking in fuṣha or 'ammiyya. To understand better how these respondents actually classified the 
different varieties, we presented them with a number of sentences that the respondents were asked to classify as fuṣhāa, 'ämmiyya/dārija or both. The sentences were not read aloud. The respondents were just given a piece of paper with the sentence on it, one sentence at a time. They were not asked to evaluate the correctness of the sentence, but just how they would classify it.

In the Rabat survey, we presented them with the following four sentences:

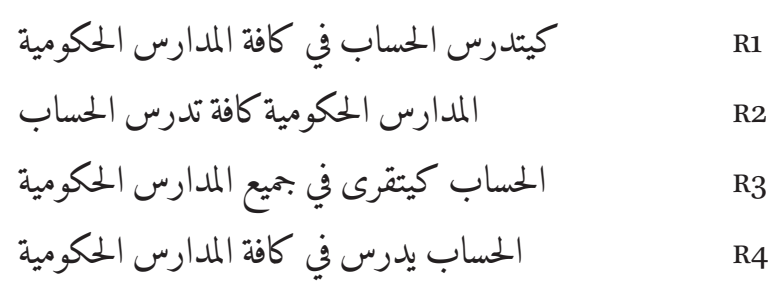

They are all varieties of a sentence that roughly translates into: "Computer science is taught in all public schools."

In Egypt the following three sentences were presented to the respondents

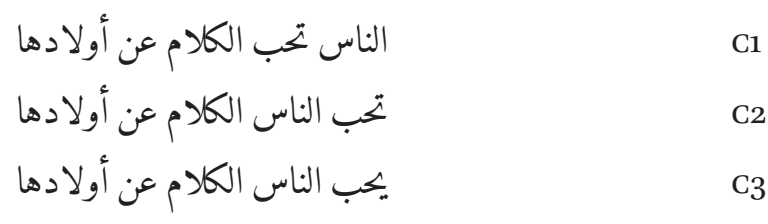

All the sentences roughly translate into: "People like to talk about their children."

All the sentences are meant to be more or less ambiguous in terms of whether a scholar would classify them as colloquial or fuṣha , but some lean more towards fuṣhā while others lean more towards the colloquial.

The results for the Rabat sentences are seen in table 1.9.

The first sentence is overwhelmingly classified as a mix, the second fush ha $\bar{a}$, the third as both or dārija, the fourth as fușhā. Interestingly, none of the sentences are classified as dārija by a majority of the population.

The results from Egypt are shown in table 1.10.

In Cairo, the trend is quite different from Rabat. While none of the Moroccan sentences were classified as dārija by a majority, all the Egyptian sentences are classified as 'ammiyya by a majority, while only a minority sees the sentences as either a mix or fuṣhā. Even C3, which quite clearly leans towards fuṣhā is only classified as such by a third of the population. 
TABLE 1.9 Classifications of dārija and

fuṣhā in Rabat

\begin{tabular}{lrrrr}
\hline & R1 & R2 & R3 & R4 \\
\hline Fușhā & 13 & 85 & 9 & 88 \\
$\begin{array}{l}\text { Dárija } \\
\text { Both }\end{array}$ & 13 & 5 & 25 & 5 \\
\hline Total & 100 & 10 & 66 & 7 \\
N = & 954 & 951 & 954 & 952 \\
\hline
\end{tabular}

TABLE 1.10 Classifications of 'āmmiyya and fușhā in Cairo

\begin{tabular}{lrrr}
\hline & C1 & \multicolumn{1}{c}{ C2 } & \multicolumn{1}{c}{ C3 } \\
\hline Fuṣhā & 19 & 24 & 35 \\
Both & 11 & 12 & 11 \\
cammiyya & 70 & 64 & 53 \\
\hline Total & 100 & 100 & 100 \\
N $=$ & 2.357 & 2.334 & 2.345 \\
\hline
\end{tabular}

The results clearly indicate that people have different perceptions of what fuṣhā and 'àmmiyya/dārija is, echoing Parkinson's findings. In addition there are differences between the two cities. It seems that in Cairo, the population has an idealized image of fuṣhā, refusing to classify anything that does not meet a very high standard as fuṣha. This could imply that the estimate for fuṣha writers is slightly under-reported in Cairo, In Rabat, however, we get the opposite picture. Even sentences with clear därija markers are understood as fuṣhā. This is interesting, as it might mean that if anything, the numbers for how often they write dārija is under-reported.

None of this changes the main direction of the findings in any significant way. However, it is clear that people do not agree on what 'ämmiyya, dārija and fuṣhā is, and that this is a subject which should be researched further. 


\section{Summing Up Findings}

The main findings from the survey can be summed up in four points. First, the colloquial varieties are frequently employed by the vast majority of the population in Cairo and Rabat. Written colloquial is not the preserve of an elite who can afford to flout conventions; it is the property of the people. Second, the population in Cairo use 'âmmiyya for a wider variety of purposes, compared to Rabat where dārija is almost exclusively used for Facebook and personal notes. Third, the Rabat population is more skeptical to the use of dārija as a written language, despite the fact that they use the variety frequently. Only a third of the population accepts it as a written variety, compared to two thirds in Cairo. Fourth, whether one writes in the colloquial is more dependent on which social group one belongs to in Rabat than in Cairo. Those with higher education have a lower likelihood of writing the colloquial in Rabat, but not in Cairo. In both cities, the young write more frequently than the old, but the impact of age on writing is significantly higher in Rabat. In Cairo, the use of ämmiyya is spread widely across all walks of life, while both practice and acceptance of 'ämmiyya remains more confined to the young with low education in Rabat.

\section{Discussion and Conclusion}

The findings of this survey open up many questions, which we hope will be subject of further research. In the final part of this chapter, we will pose some of these questions and suggest some angles from which the findings could be interpreted. First, why is the colloquial so widespread?

The survey findings underscore and corroborate qualitative research that has noted an increase of writing in the colloquial (for example Daoudi 2011, Elinson 2011, Doss et al 2013). How to account for the frequent usage of this variety? One possible explanation is the increasing level of literacy in Egypt and Morocco. When literacy spreads, writing is no longer confined to formal channels, but becomes widespread in the households of ordinary people. There the need for a more informal style of writing might arise, as fușhā is generally seen as too formal to use in interpersonal communication, be it written or oral, as suggested by Belnap and Bishop (2003). Walters similarly argues that informality is key to understanding why people write in the colloquial rather than standard (Walters 2003: 98).

With the internet revolution, there has been an enormous increase in platforms designed for informal written communication. Facebook and Twitter are certainly platforms associated with informal writing, and as such with the colloquial (Abu Elijah 2014, Warschauer et al 2002). The spread of channels where 
informal writing is not only accepted, but expected, could be an important reason for the high prevalence of āmmiyya in Cairo and dārija in Rabat. This hypothesis is also strengthened by the fact that Facebook and personal writing are the dominant platforms where the colloquial is being written.

In terms of attitudes, a substantial portion of the population accepts the colloquial as a written language. At the same time fușhā remains a highly valued variety in both Cairo and Morocco, existing alongside the high acceptance of 'ammiyya as a written language. In other words, the fact that people accept 'ammmiyya does not mean that they value fuṣha less. This also relates to writing practices. Those who write in 'àmmiyya or dārija also write in fușhā. More dārija and 'āmmiyya just means more writing, not less fușhā.

Second, why is 'ämmiyya more widespread than därija? Here we can only offer speculations. The findings point to clear differences between Cairo and Rabat in terms of practices and attitudes. The use of the colloquial is more confined in terms of social groups and which platforms it is used in Rabat compared to Cairo. The Rabat population is also less prone to accepting the colloquial as a written variety. One possible explanation might be that Egypt has a longer tradition for writing 'ämmiyya than Morocco has for writing dārija. There are writings in ämmiyya dating back to the $16 \mathrm{~h}$ century, and aside from a break around the end of the 19th century and early 20 th century, there was a steady production of both literature, theater and news articles written in Egyptian dialect (Doss et al 2013). Although there are examples of historical dārija writing, it was not as widespread as Egypt.

Part of the explanation might also lie in the different roles the Arabic language has played in Moroccan and Egyptian nationalism. Suleiman (2003) argues that language has become an essential part of the national identity in all Arab countries. This process had very different outcomes in Egypt and Morocco. In Egypt, the local colloquial dialect became a tool for nationalism. As early as the 19th century there was "a deep desire among the Egyptian nationalists to reform the language by bringing it closer to the colloquial, the spoken language of the people" (Suleiman 2003:174). Recently, Ziad Fahmy has shown that the colloquial was an important part of nationalist, popular culture at the turn of the 19th century (Fahmy 2011). In other words, to use the colloquial was not necessarily seen as corrupting the Arabic language, but rather as a part of asserting your Egyptian identity.

In Morocco on the other hand, national identity was not connected to dārija as much as to fușhā. After independence large-scale Arabization programs were introduced, with the main goal of promoting fuṣha $\bar{a}$, at the expense of French. This might have contributed to a sense that fuṣha was the language connected to the Moroccan national identity, rather than dārija. This very 
different interpretations and frames for understanding the local dialect might be an explanation for the support for fuṣha as the only written Arabic language in Morocco and the more open attitude towards ämmiyya as a written language in Cairo.

This chapter is the first to establish a quantitative estimate of how often 'ammiyya and dārija is written and how it is perceived drawing on samples representative of the whole literate population in Cairo and Rabat. While the estimates have to be interpreted with caution, it is clear that the populations of Rabat and Cairo write dārija and 'ämmiyya frequently. It is also clear that this trend holds true across social groups, especially in Cairo. However, there are also differences between the cities, with Rabat being more conservative. An important factor that merits more research is how people classify fuṣha and the colloquial varieties. We have documented that there are clear differences, but research should pursue the question of exactly what is classified as colloquial and what is classified as fuṣhā in the Arab world. Despite the frequent use and acceptance of the colloquial varieties in these surveys, there are no indications that the spread of the colloquial is a threat to the significance of fușha $\bar{a}$, which seems to retain its position as a prestigious language, alongside the colloquial varieties. In our view, these findings open up new and interesting pathways to study developments in written Arabic.

\section{References}

Abu Elhija, Dua’a. 2014. "A New Writing System? Developing Orthographies for Writing Arabic Dialects in Electronic Media," Writing Systems Research 6(2), 2014:190-214.

Belnap, R. Kirk and Brian Bishop. 2003. "Arabic Personal Correspondence: A Window on Change in Progress?," International Journal of the Sociology of Language 163: 9-25. Bertrand, Marianne, and Sendhil Mullainathan. 2001 "Do People Mean What They Say? Implications for Subjective Survey Data." American Economic Review, 91(2): 67-72.

Daoudi, Anissa. 2011. "Globalization, Computer-Mediated Communications and the Rise of E-Arabic," Middle East Journal of Culture and Communication 4(2):146-163.

Doss, Madiha and Humphfrey Davies. 2013. al-'āmmiyy a al-mișriyy a al-maktūba, Cairo, The General Egyptian Book Organization.

Elinson, Alexander. 2011. "Dārija and changing writing practices in Morocco" International Journal of Middle East Studies. 45(4):715-730.

Fahmy, Ziad. 2011. Ordinary Egyptians: Creating the Modern Nation through Popular Culture. Palo Alto: Stanford University Press.

Haeri, Niloofar. 2003. Sacred Language, Ordinary People: Dilemmas of Culture and Politics in Egypt, New York, Palgrave Macmillan. 
Jerolmack, Colin and Shamus Khan. 2014. "Talk Is Cheap: Ethnography and the Attitudinal Fallacy" Sociological Methods \& Research, 43:178-209.

Kindt, Kristian T. and Jacob Høigilt and Tewodros Kebede Forthcoming "Writing Change Diglossia and popular writing practices in Egypt" in Arabica, forthcoming.

Kindt, Kristian T. and Tewodros A. Kebede Forthcoming, "Language change in Egypt: A tabulation report" Fafo-report, forthcoming.

Kebede, Tewodros A. and Kristian Takvam Kindt and Jacob Høigilt 2013. "Language Change in Egypt: Social and Cultural Indicators Survey: A Tabulation Report", Faforeport 2013:39.

Kreuter, Frauke and Stanley Presser and Roger Tourangeau. 2008. "Social Desirability Bias in CATI, IVR, and Web Surveys: The Effects of Mode and Question Sensitivity." Public Opinion Quarterly. 72:847-865.

LaPiere, Richard T. 1934. "Attitudes vs. Actions", Social Forces. 13:230-237.

Meskine, Driss and Jan Jaap Ruiter. 2015. "Young Moroccans are speaking out: The changing language market of Morocco" Sociolinguistic Studies 9(1).

Milroy, James and Lesley Milroy. 1999. Authority in Language Investigating Standard English, London and New York, Routledge.

Parkinson, Dilworth B. 1991. "Searching for Modern Fuṣhā: Real-Life Formal Arabic," alArabiyya 24:31-64.

Parkinson, Dilworth B. 1993. "Knowing Standard Arabic: Testing Egyptians' MSA Abilities," in Current Issues in Linguistic Theory, ed. Mushira Eid and Clive Holes 101, Amsterdam, John Benjamins Publishing Company.

Parkinson, Dilworth B. 2003. "Verbal Features in Oral Fuṣhā Performances in Cairo," International Journal of the Sociology of Language (163):27-41.

Schuman, H. and Michael P. Johnson. 1976. "Attitudes and Behavior" Annual Review of Sociology. 2:161-207.

Silver, Nate. 2013. The Signal and the Noise: Why so many predictions fail, and some don't. Penguin Group.

Suleiman, Yasir. 2003. The Arabic Language and National Identity: A Study in Ideology. Georgetown University Press.

Tourangeau, R. and T. Yan. 2007. "Sensitive questions in surveys". Psychological bulletin, 133(5).

Vaisey, Stephen. 2014. "The "Attitudinal Fallacy" Is a Fallacy: Why We Need Many Methods to Study Culture". Sociological Methods \& Research 43: 227-231.

Walters, Keith. 2007. "Language Attitudes" in Encyclopedia of Arabic Language and Linguistics, Edited by Kees Versteegh. Amsterdam, Brill.

Walters, Keith. 2003. "Fergie's prescience: the changing nature of diglossia in Tunisia". International Journal Of The Sociology Of Language, (163):77-109.

Warschauer, Mark and Ghada R El Said and Ayman G. Zohry. 2002. "Language Choice Online: Globalization and Identity in Egypt," Journal of Computer-Mediated Communication $7(4)$. 